Article

\title{
Raman Spectroscopy Studies on the Barocaloric Hybrid Perovskite $\left[\left(\mathrm{CH}_{3}\right)_{4} \mathrm{~N}\right]\left[\mathrm{Cd}\left(\mathrm{N}_{3}\right)_{3}\right]$
}

\author{
Rosivaldo Xavier da Silva ${ }^{1}\left(\right.$, Carlos William de Araujo Paschoal ${ }^{2}$, \\ Clenilton Costa dos Santos ${ }^{3}{ }^{\mathbb{D}}$, Alberto García-Fernández ${ }^{4}{ }^{(0)}$, Jorge Salgado-Beceiro ${ }^{4}{ }^{(\mathbb{D}}$, \\ María Antonia Señarís-Rodríguez ${ }^{4, *(D)}$, Manuel Sanchez-Andujar ${ }^{4}$ and \\ Ariel Nonato Almeida de Abreu Silva ${ }^{5, *}$ \\ 1 Coordenação de Ciências Naturais, Universidade Federal do Maranhão, Campus VII, São Luís 65400-000, \\ Brazil; rosivaldo.xs@ufma.br \\ 2 Departamento de Física, Universidade Federal do Ceará, Fortaleza 65455-900, Brazil; \\ paschoal.william@fisica.ufc.br \\ 3 Departamento de Física, CCET, Universidade Federal do Maranhão, São Luís 65085-580, Brazil; \\ clenilton.cs@ufma.br \\ 4 Departamento de Química, Facultade de Ciencias y CICA, Universidade da Coruña, 15071 A Coruña, Spain; \\ alberto.garcia.fernandez@udc.es (A.G.-F.); jorge.salgado@udc.es (J.S.-B.); m.andujar@udc.es (M.S.-A.) \\ 5 Coordenação de Ciências Naturais, Universidade Federal do Maranhão, Campus do Bacabal, \\ São Luís 65700-000, Brazil \\ * Correspondence: m.senaris.rodriguez@udc.es (M.A.S.-R.); ariel.nonato@ufma.br (A.N.A.d.A.S.); \\ Tel.: +34-981-167000 (ext. 2013) (M.A.S.-R.); +55-98-982054803 (A.N.A.d.A.S.)
}

Academic Editor: Derek J. McPhee

Received: 29 September 2020; Accepted: 14 October 2020; Published: 16 October 2020

\begin{abstract}
Temperature-dependent Raman scattering and differential scanning calorimetry were applied to the study of the hybrid organic-inorganic azide-perovskite $\left[\left(\mathrm{CH}_{3}\right)_{4} \mathrm{~N}\right]\left[\mathrm{Cd}\left(\mathrm{N}_{3}\right)_{3}\right]$, a compound with multiple structural phase transitions as a function of temperature. A significant entropy variation was observed associated to such phase transitions, $|\Delta S| \sim 62.09 \mathrm{~J} \cdot \mathrm{kg}^{-1} \mathrm{~K}^{-1}$, together with both a positive high barocaloric $(\mathrm{BC})$ coefficient $\left|\delta \mathrm{T}_{\mathrm{t}} / \delta \mathrm{P}\right| \sim 12.39 \mathrm{~K} \mathrm{kbar}^{-1}$ and an inverse barocaloric (BC) coefficient $\left|\delta \mathrm{T}_{\mathrm{t}} / \delta \mathrm{P}\right| \sim-6.52 \mathrm{kbar}^{-1}$, features that render this compound interesting for barocaloric applications. As for the obtained Raman spectra, they revealed that molecular vibrations associated to the $\mathrm{NC}_{4}, \mathrm{~N}_{3}{ }^{-}$and $\mathrm{CH}_{3}$ molecular groups exhibit clear anomalies during the phase transitions, which include splits and discontinuity in the phonon wavenumber and lifetime. Furthermore, variation of the $\mathrm{TMA}^{+}$and $\mathrm{N}_{3}{ }^{-}$modes with temperature revealed that while some modes follow the conventional red shift upon heating, others exhibit an unconventional blue shift, a result which was related to the weakening of the intermolecular interactions between the TMA (tetramethylammonium) cations and the azide ligands and the concomitant strengthening of the intramolecular bondings. Therefore, these studies show that Raman spectroscopy is a powerful tool to gain information about phase transitions, structures and intermolecular interactions between the A-cation and the framework, even in complex hybrid organic-inorganic perovskites with highly disordered phases.
\end{abstract}

Keywords: azide frameworks; hybrid perovskite; Raman spectroscopy; phase transitions

\section{Introduction}

Compounds that combine simultaneously organic and inorganic chemical groups are of great interest since they enlarge the range of structural possibilities that allow the coexistence and modulation of fundamental physical properties, increasing their multifunctional potential [1]. These hybrid 
inorganic-organic compounds have attracted great attention in the last years in view of their high technological potential in the areas of optoelectronics [2], photovoltaics [3], ferroelectrics [4], multiferroics [5,6], and, very recently, also in the field of barocaloric materials for solid-state cooling $[7,8]$.

In this context, the $\mathrm{ABX}_{3}$ perovskite family-which, for decades, has played a prominent role in the evolution and application of inorganic materials-has experienced a large expansion by incorporating organic blocks in its structure, giving rise to very outstanding materials known as hybrid perovskites. In these relatively new compounds, the A site is usually occupied by an organic cation $(\mathrm{A}=$ protonated amine), the $\mathrm{B}$ site may be occupied by a divalent transition metal cation (e.g., $\mathrm{B}=\mathrm{Mn}^{2+}, \mathrm{Co}^{2+}, \mathrm{Ni}^{2+}$, $\mathrm{Cd}^{2+}$, etc.) and the $\mathrm{X}$ site by a monatomic anion, mainly a halide, such as $\mathrm{Cl}^{-}, \mathrm{Br}^{-}$and $\mathrm{I}^{-}$, or anionic polyatomic bridge ligands-for instance, azides $\left(\mathrm{N}_{3}^{-}\right)$, cyanides $\left(\mathrm{CN}^{-}\right)$and formates $\left(\mathrm{HCOO}^{-}\right)[1,9-11]$.

The introduction of elongated bridge ligands in the $X$ site allows the building of frameworks that can accommodate a high variety of larger organic ions in the A site, giving rise to structures that are, in general, more flexible and susceptible to phase transformations as compared to those built using shorter $X[12,13]$. In this context, hybrid perovskites with $X=$ azide $\left(\mathrm{N}_{3}{ }^{-}\right)$and general formula $\left[\left(\mathrm{CH}_{3}\right)_{\mathrm{n}} \mathrm{NH}_{4-\mathrm{n}}\right]\left[\mathrm{M}\left(\mathrm{N}_{3}\right)_{3}\right], \mathrm{n}=1-4$, where $\mathrm{M}$ : divalent metallic cation or bimetallic combinations of $\mathrm{M}^{3+} \mathrm{M}^{+}$are very attractive in view of their interesting ferroic properties [6] and extensive structural transitions $[11,14,15]$. In these materials where the azide groups act as end-to-end $\left(\mathrm{EE}, \mu-1,3-\mathrm{N}_{3}\right)$ almost linear bridging ligands, magnetic coupling between metallic centers is also more favored than in hybrids with other polyatomic ligands, so azide perovskites typically exhibit higher magnetic transition temperatures than other analogous hybrids, such as formate perovskites. [16,17].

A very prominent member of this family is the manganese azide with $\mathrm{A}:\left[\left(\mathrm{CH}_{3}\right)_{4} \mathrm{~N}\right]^{+}(\mathrm{n}=4)$, (TMA), (TMAMnN 3 ), the first azide reported to have a three-dimensional framework structure [17], which is now known to show coexistence of three ferroic orders (antiferroelectric, ferroelastic and magnetic bistability) [6,16]. In addition, in view of its very large entropy change at the ferroelastic phase transition (two times larger than in the case of the giant barocaloric hybrid perovskite [TPrA] $\left[\mathrm{Mn}(\mathrm{dca})_{3}\right]$ $\left(\mathrm{TPrA}=\left(\mathrm{CH}_{3} \mathrm{CH}_{2} \mathrm{CH}_{2}\right)_{4} \mathrm{~N}^{+}\right.$, dca $\left.=\left[\mathrm{N}(\mathrm{CN})_{2}\right]^{-}\right)$[8]), it has been first proposed [6] and recently experimentally proved that this material is a very promising barocaloric material [18].

By replacing $\mathrm{B}: \mathrm{Mn}^{2+}$ with $\mathrm{Cd}^{2+}$, the Cd-azide perovskite $\left[\left(\mathrm{CH}_{3}\right)_{4} \mathrm{~N}\right]\left[\mathrm{Cd}\left(\mathrm{N}_{3}\right)_{3}\right]\left(\mathrm{TMACdN}_{3}\right)$ is obtained, which can be described as consisting of three-dimensional anionic cages $\left[\mathrm{Cd}\left(\mathrm{N}_{3}\right)_{3}\right]-$ containing TMA as A-cation [19]. This compound is even more susceptible to structural transformations than the Mn-azide as it exhibits three reversible first-order structural phase transitions as a function of temperature (from phase $\alpha$ to phase $\beta$ (at $\mathrm{T}=270 \mathrm{~K}$ ), from phase $\beta$ to phase $\gamma$ at $\mathrm{T}=277 \mathrm{~K}$ and from phase $\gamma$ to phase $\delta$ at $\mathrm{T}=322 \mathrm{~K}$ ). According to the literature, such transformations imply order-disorder processes related mainly to the sway of the conjugated $\mathrm{N}=\mathrm{N}=\mathrm{N}$ bonds, as well as tetrahedron rotations of the A-cation $\left[\left(\mathrm{CH}_{3}\right)_{4} \mathrm{~N}\right]^{+}$[15]. In this context, and according to the literature, at temperatures up to $270 \mathrm{~K}$, the crystal structure of this compound is a centrosymmetric space group C2/c (No. 15, Z = 4) ( $\alpha$-phase). As it can be seen in Figure 1, in this polymorph, the $\left[\mathrm{Cd}\left(\mathrm{N}_{3}\right)_{3}\right]^{-}$framework is considerably distorted, the azide ligands-which are slightly bent-are completely ordered and the $\mathrm{TMA}^{+}$cations are centered in the A-sites. There is also a cooperative tilting of the [CdN 6 ] octahedra. At $270 \mathrm{~K}$, on heating, this polymorph transforms into a $\beta$ phase, with a narrow stability range of only $7 \mathrm{~K}$ that hinders its structural characterization [15]. Upon further heating, at $277 \mathrm{~K}$, this polymorph transforms into the $\gamma$-phase, which is monoclinic, with space group $P 2_{1} / m$. This polymorph is characterized by a subtle disorder in the slightly bent azide ligands along the direction [010], as shown in Figure 1, where the two $\mathrm{N}$ atoms $\left(\mathrm{N} 3, \mathrm{~N}^{\prime}\right)$ that bind the $\mathrm{Cd}$ ions alternate between two crystallographic positions (Wyckoff site 4f), while the third one (N4) occupies a unique site (4e). Meanwhile, the other $\mathrm{N}_{3}{ }^{-}$ bridges are ordered and completely linear. Another interesting feature is the considerable distortion of the $\left[\mathrm{Cd}\left(\mathrm{N}_{3}\right)_{3}\right]^{-}$framework, with an also slightly distorted octahedral environment for the $\mathrm{Cd}^{2+}$ cations (three different $\mathrm{Cd}-\mathrm{N}$ distances) and an unconventional cooperative tilting of such octahedra, where adjacent octahedra display a cooperative in-phase rotation within the ac plane (all of them are rotated either clockwise or counter-clockwise), while along the b-axis, adjacent octahedra are oppositely 
rotated (alternating clockwise and counter-clockwise rotations); see Figure S2 of the supplementary materials. This unconventional tilting cannot exist in pure inorganic $\mathrm{ABO}_{3}$ perovskites.

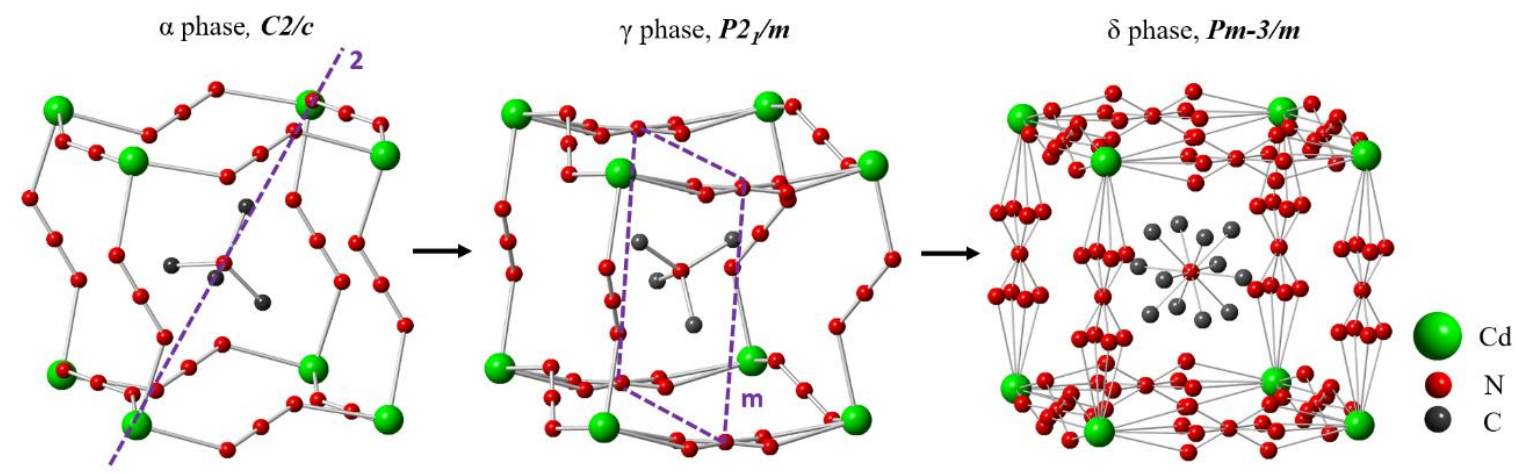

Figure 1. Perspective view of the crystal structures of the $\alpha, \gamma$ and $\delta$ phases of $\left[\left(\mathrm{CH}_{3}\right)_{4} \mathrm{~N}\right]\left[\mathrm{Cd}\left(\mathrm{N}_{3}\right)_{3}\right]$. $\mathrm{Cd}, \mathrm{N}$ and $\mathrm{C}$ atoms are shaded in green, red and dark gray, respectively.

Another interesting feature of this polymorph is the off-center shift of the TMA from the center of the cavities.

At temperatures above $322 \mathrm{~K}, \mathrm{TMACdN}_{3}$ transforms into a cubic phase ( $\delta$-phase), belonging to the Pm-3m space group (No. 221, Z = 1) [15], characterized by a large structural disorder of the azide ligands, where the rod-like $\mathrm{N}_{3}$ oscillates among four sites. Another significant feature is the disorder in $\mathrm{TMA}^{+}$, where the four (4) positions of the carbon ions in $\mathrm{TMA}^{+}$cation unfold into 12 positions, as illustrated in Figure 1.

In this paper, we try to gain more insight into such phase transformations and in the role of interactions between the A-cation and the framework in such structural transitions, an aspect that has not been analyzed so far in this compound. For this purpose, we use Raman spectroscopy as a tool that can be very powerful to study the mechanisms of structural phase transitions, to detect effects of order-disorder and to clarify how symmetry breaks; specifically, which vibrations, ions and molecular arrangements are strongly related to the given phase transitions [20-27]. Furthermore, from differential scanning calorimetric (DSC) measurements and structural data available in the literature, we estimate the barocaloric coefficients $\left(\left|\delta \mathrm{T}_{\mathrm{t}} / \delta \mathrm{P}\right|\right)$ and entropy changes for each of these transitions to evaluate the potential of this compound as barocaloric material.

\section{Results and Discussion}

\subsection{Basic Characterization and Deeper Insight into the Crystal Structure of $T M A C d N_{3}$}

Room-temperature experimental X-ray powder diffraction results confirmed that the obtained sample of $\mathrm{TMACdN}_{3}$ is single phase as no impurities were present, and that at this temperature, it exhibits the expected crystal structure for the $\gamma$-phase. Details of the comparison between the experimental X-ray powder diffraction pattern of $\mathrm{TMACdN}_{3}$ at room temperature and the simulated $X$-ray diffraction pattern from single crystal measurements available in the literature [15] are given in the Supporting Information (see Figure S1).

On the other hand, to gain more insight into the phase transitions, we analyzed, in detail, the intermolecular interactions between the TMA cation and the $\left[\mathrm{Cd}\left(\mathrm{N}_{3}\right)_{3}\right]^{-}$framework of the different polymorphs on the basis of the Hirshfeld surface analysis; see Fig. S3 of SI. This analysis shows that there are interactions between the $\mathrm{H}$ atoms of the TMA cation and the $\mathrm{N}$ atoms of the azide ligands (red regions at the Hirshfeld surface) both in the $\alpha$ - and $\gamma$-polymorphs. In addition, we observed that there are differences between the number of azide ligands involved in these interactions in each of these polymorphs. In the case of $\alpha$-phase, the azide ligands (except the four along the a-axis) are all involved in the link with the TMA cation. Meanwhile, only two azide ligands (those located along 
the b-axis) are involved in such interactions in the case of the $\gamma$-phase. It is worth noting that these two different situations are also related to the location of the TMA inside of the pseudocuboctahedral cavity. In this context, as in the $\alpha$-phase, the TMA cation is located at the center of the cavity and most of the azide ligands can interact with that cation. In contrast, in the case of the $\gamma$-phase, where the TMA cation is shifted from center of the cavity towards two of the azide ligands, those $\mathrm{N}_{3}{ }^{-}$are the only ones that can interact with it.

During the discussion of the Raman results, we will show how these interactions between the TMA cation and the azide ligands, which are strongly influenced by temperature change, especially in the phase transition regions, are reflected and can be followed through the Raman spectra profile.

\subsection{Thermal Characterization (DSC) and Barocaloric Parameters}

DSC measurements confirm that the compound undergoes three reversible structural phase transitions as a function of temperature with $\mathrm{T}_{\text {heating }} / \mathrm{T}_{\text {cooling }}=270 / 263,277 / 270$ and 322/319 $\mathrm{K}$, with an overlap of the peaks of the first two transitions $(\alpha \rightarrow \beta$ and $\beta \rightarrow \gamma)$ and a sharp peak regarding the ferroelastic transition $(\gamma \rightarrow \delta)$ (see Figure 2a). From the area under the peaks, we have obtained the isobaric enthalpy change $\Delta H_{i b}$ for the $\alpha \rightarrow \beta \rightarrow \gamma$ transitions, which were analyzed jointly, and ferroelastic transition; see obtained values in Table 1. Additionally, we have also calculated the isobaric entropy change $\Delta S_{\mathrm{ib}}$ as a function of temperature using the following relation $\Delta S_{i b}=\int_{T_{0}}^{T} \frac{1}{T} \frac{Q(P)}{T^{\prime}} d T$, where $Q(P)$ is the heat flow measured at constant pressure, $T^{\prime}$ is the temperature rate and $T$ is the temperature, as it is shown in Figure $2 b$. The isobaric entropy change as a function of temperature grows abruptly until it reaches a local maximum plateau of $\sim 29.83 \mathrm{~J} \cdot \mathrm{Kg}^{-1} \mathrm{~K}^{-1}$ at the transition $\alpha \rightarrow \beta \rightarrow \gamma$ and $\sim 32.26 \mathrm{~J} \cdot \mathrm{Kg}^{-1} \mathrm{~K}^{-1}$ at the ferroelastic transition. Therefore, the total entropy change for the three phase transitions turns to be $62.09 \mathrm{~J} \cdot \mathrm{kg}^{-1} \mathrm{~K}^{-1}$, which is in excellent agreement with the value reported in the literature $[15,26]$.

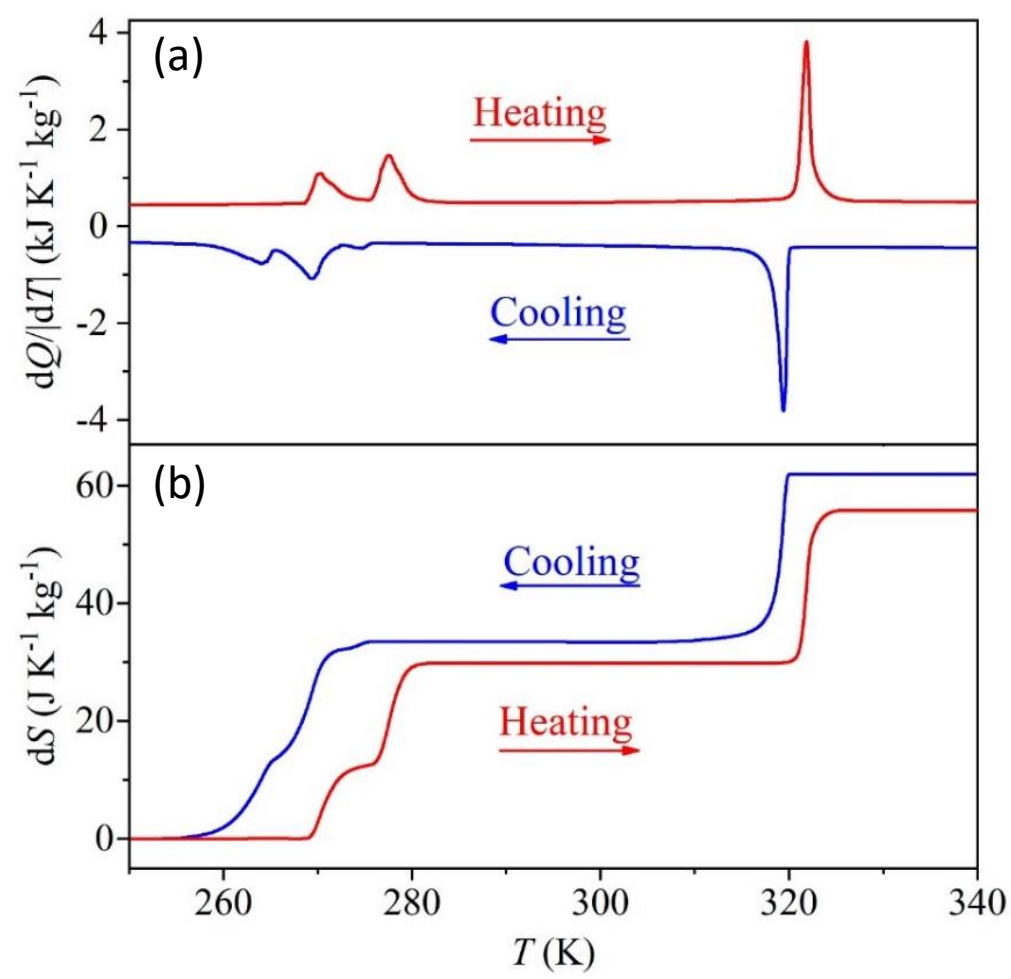

Figure 2. (a) Differential scanning calorimetric (DSC) results as a function of temperature obtained by heating and cooling the $\mathrm{TMACdN}_{3}$ compound. (b) Isobaric entropy change as a function of temperature due to the first-order phase transitions $\alpha \rightarrow \beta \rightarrow \gamma$ and $\gamma \rightarrow \delta$ (obtained from experiments performed on heating and cooling). 
Table 1. Summary of thermodynamic parameters for the phase transitions of $\mathrm{TMACdN}_{3}$ compound obtained from DSC analysis under heating and cooling. $\left|\Delta H_{i b}\right|$ is the isobaric enthalpy change, $\left|\Delta S_{i b}\right|$ is the isobaric entropy change, $\mathrm{N}$ is the number of sites in the disordered phase and $\delta T_{t} / \delta P$ is the barocaloric coefficient.

\begin{tabular}{ccccc}
\hline \multirow{2}{*}{ Parameters } & \multicolumn{2}{c}{ Heating } & \multicolumn{2}{c}{ Cooling } \\
\cline { 2 - 5 } & $\mathbf{T}_{\boldsymbol{\alpha} \rightarrow \boldsymbol{\beta}} / \mathbf{T}_{\boldsymbol{\beta} \rightarrow \gamma}$ & $\mathbf{T}_{\gamma \rightarrow \mathcal{\delta}}$ & $\mathbf{T}_{\boldsymbol{\alpha} \leftarrow \beta} / \mathbf{T}_{\boldsymbol{\beta} \leftarrow \gamma}$ & $\mathbf{T}_{\boldsymbol{\gamma} \leftarrow \mathcal{\delta}}$ \\
\hline$T_{t}(\mathrm{~K})$ & $270.4 / 277.6$ & 322.0 & $263.9 / 269.6$ & 319.5 \\
$\left|\Delta H_{i b}\right|\left(\mathrm{J} \cdot \mathrm{g}^{-1}\right)$ & 8.40 & 8.46 & 9.22 & 9.14 \\
$\left|\Delta S_{i b}\right|\left(\mathrm{J} \cdot \mathrm{Kg}^{-1} \mathrm{~K}^{-1}\right)$ & 29.83 & 25.97 & 32.26 & 28.51 \\
$\mathrm{~N}$ & 2.9 & 2.5 & 3.2 & 2.8 \\
$\delta T_{t} / \delta P\left(\mathrm{~K} \mathrm{kbar}^{-1}\right)$ & 12.39 & -6.52 & - & - \\
\hline
\end{tabular}

As in order-disorder phase transitions, $\Delta \mathrm{S}$ is given by $\mathrm{R} \ln (\mathrm{N})$ with $N=\left(n_{2} / n_{1}\right)$, where $n_{2}$ and $n_{1}$ are the number of configurations in each polymorph and $\mathrm{R}$ is the gas constant $\left(8.314 \mathrm{~J} \mathrm{~mol}^{-1} \mathrm{~K}^{-1}\right)$, we have estimated, from the heating data, an $\mathrm{N}=2.9$ and 2.5 for the $\alpha \rightarrow \beta \rightarrow \gamma$ transition and ferroelastic, respectively. All the values of enthalpy change $\Delta \mathrm{H}$, entropy change $\Delta \mathrm{S}$ and $\mathrm{N}$ under heating and cooling are summarized in Table 1.

Additionally, following the procedure reported in the literature [7], we have estimated different barocaloric parameters to evaluate the potential of this hybrid perovskite as a barocaloric material.

In this context we have to note that $\mathrm{TMACdN}_{3}$ shows relevant features, which, in principle, render it a good candidate to show high barocaloric effects, especially as it has a relative large reversible ferroelastic structural transition, whose critical temperature is close to room temperature, making it highly desirable for practical applications; the intrinsic flexibility of the azide ligand, which is part of the framework, makes it susceptible to large volume variations under applied external pressure.

To estimate the barocaloric (BC) coefficient of TMAC $\mathrm{CN}_{3}$, we have used the Clausius-Clapeyron method, which is a widely used indirect method in the case of caloric materials [7]. Taking into account the following expression, $(\delta \mathrm{Tt} / \delta \mathrm{P})=(\Delta v / \Delta \mathrm{S})$, where $\Delta v$ is the volume change at the phase transition and $\Delta S$ is the entropy change of the phase transition, we calculate the BC coefficient from our calorimetric results (on heating) as well the structural data (volume) in the vicinity of the structural transition available in the literature [28]. Following this method, we have estimated the barocaloric coefficient for the $\alpha \rightarrow \beta \rightarrow \gamma$ phase transition and for $\gamma \rightarrow \delta$, as shown in Table 1. As it can be seen there, the two barocaloric coefficients are very different, not only in magnitude (one almost double than the other) but also in sign. In this context, while the $\alpha \rightarrow \beta \rightarrow \gamma$ phase transition exhibits a positive, conventional BC coefficient (which means that the $\gamma$ phase heats up when adiabatically squeezed and cools down when pressure is released close to this phase transition temperature), the ferroelastic $\gamma \rightarrow \delta$ transition displays a negative, that is, inverse, BC coefficient (that is, the $\gamma$ phase cools down when pressure is applied and heats up when it is released close to the ferroelastic phase transition temperature).

For the $\alpha \rightarrow \beta \rightarrow \gamma$ phase transitions, the BC coefficient is $12.39 \mathrm{~K} \mathrm{kbar}^{-1}$, which is similar to that exhibited by the related azide hybrid perovskite $\mathrm{TMAMnN}_{3}$ [18]. In any case, it is worth to note that the BC coefficient of $\mathrm{TMACdN}_{3}$ is very large in comparison with $\mathrm{BC}$ inorganic compounds (such as alloys and oxides), which typically exhibit values inferior to $1 \mathrm{~K} \mathrm{kbar}^{-1}$ [29]. Very interestingly, the ferroelastic transition displays an inverse $\mathrm{BC}$ coefficient, which is very scarce, and few materials are known with this property. Therefore, the $B C$ parameters indicate that $\mathrm{TMACdN}_{3}$ is an interesting material from $\mathrm{BC}$ applications with an adequate working temperature, close to room temperature between 260 and $320 \mathrm{~K}$, and isobaric entropy change values almost similar to those reported for related $[\operatorname{TPrA}]\left[\mathrm{Mn}(\mathrm{dca})_{3}\right]$ hybrid perovskite, whose values is $38.1 \mathrm{~J} \cdot \mathrm{Kg}^{-1} \mathrm{~K}^{-1}$ (until now the highest report value for a $\mathrm{BC}$ hybrid perovskite). 


\subsection{Raman Studies}

\subsubsection{Room Temperature Raman Spectrum}

Figure 3 shows the Raman spectrum obtained for $\mathrm{TMACdN}_{3}$ at room temperature, which, in fact, is rather similar to that observed for $\mathrm{TMAMnN}_{3}$ and $\mathrm{DMAMnN}_{3}$ [24] compounds. According to group theory, considering the irreducible representations of the group factor $\mathbf{C}_{2 h}(2 / m)$ and the occupations of the Wyckoff sites of the space group $\mathbf{C}_{2 h}{ }^{2}\left(P 2_{1} / m\right), 72$ Raman active modes are predicted $\left(\Gamma^{\text {Raman }}=38 A_{g} \oplus 34 B_{g}\right)$. Among those, 33 modes were observed, being a reasonable number considering that in these compounds, a large grouping of modes is expected in narrow bands of the spectrum. The vibrational modes investigated are mainly attributed to internal vibrations of the $\mathrm{TMA}^{+}$cations, azide anions and lattice vibrations [24]. Most internal modes of $\mathrm{TMA}^{+}$cations and azide ligands are observed in distinct regions of the spectrum, which facilitates the assignment and comparison with similar compound spectra. Thus, our assignment of the observed modes was based on Raman investigations of similar compounds available in literature [23,29-31] and it is summarized in Table 2.
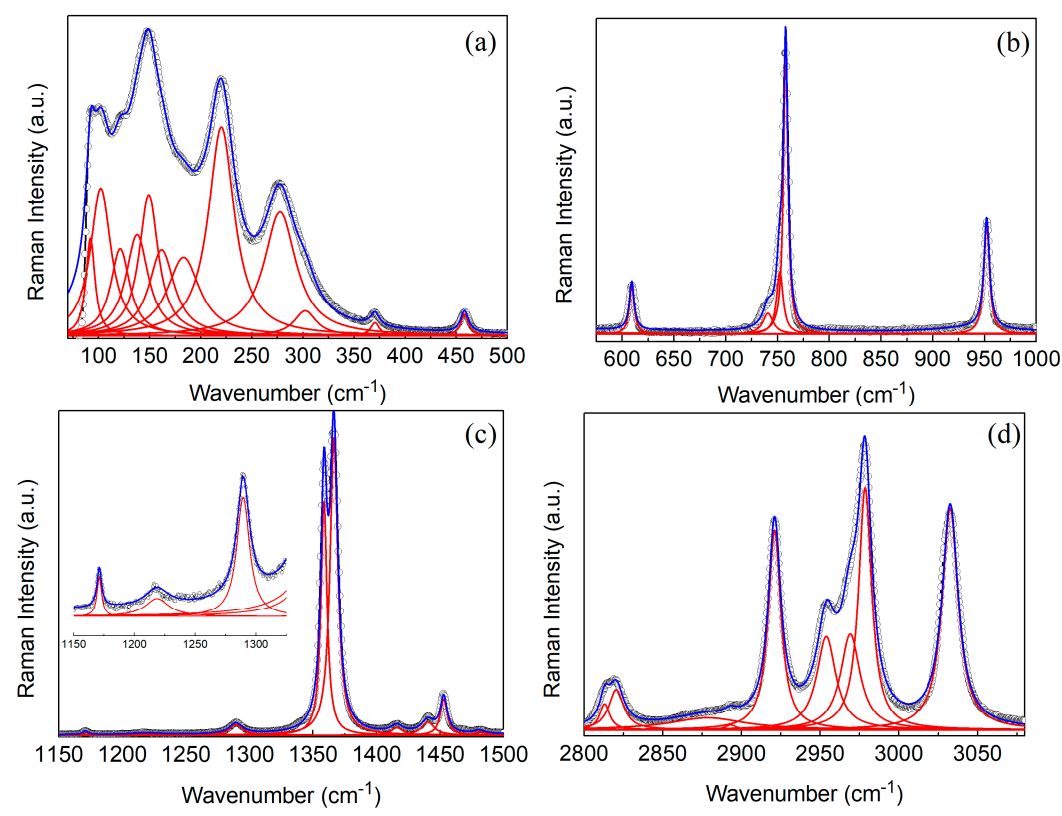

Figure 3. (a-d) show Raman spectra of $\mathrm{TMACdN}_{3}$ measured at room temperature in different spectral regions. The open circles are the experimental data, while the blue line is the best fit employing Lorentzian's function. The inset at figure (c) shows a zoom of the medium-wavenumber region of the spectrum.

As can be seen there, at frequencies below $300 \mathrm{~cm}^{-1}$, lattice modes are mainly observed and include translational and librational modes of the $\mathrm{TMA}^{+}$cations, $\mathrm{N}_{3}{ }^{-}$organic groups as well as those of $\mathrm{Cd}^{2+}$ ions. In this region, less pure modes are also observed, with quite representative intensities, such those at 220 and $274 \mathrm{~cm}^{-1}$, which can be classified as $\mathrm{N}_{3}{ }^{-}$librations and a combination of $\mathrm{CH}_{3}$ group twisting with an $\mathrm{Cd}$ ion translation, respectively.

The intermediate- and high-frequency regions are dominated by internal modes. A rather prominent mode attributed to the symmetric stretching of the $\mathrm{NC}_{4}$ group is observed at approximately $758 \mathrm{~cm}^{-1}$. The region between $1000-1500 \mathrm{~cm}^{-1}$ exhibits several low-intensity modes mainly due to $\mathrm{CH}_{3}$ rocking ( $\rho$ modes) observed at about 1047, 1171, 1218 and $1359 \mathrm{~cm}^{-1}$ and $\delta$-bending (scissoring) of $\mathrm{CH}_{3}$ group $\left(\delta_{\mathrm{as}} \mathrm{CH}_{3} \delta_{\mathrm{s}} \mathrm{CH}_{3}\right)$ as the mode at $1453 \mathrm{~cm}^{-1}$. This band also includes the azide group symmetric stretching ( $v_{1}$ mode) at $1359 \mathrm{~cm}^{-1}$, which is a very intense and important mode for monitoring the azide ligands $\mathrm{N}_{3}{ }^{-}$(see Table 2 ). 
In the higher-frequency region, above $2000 \mathrm{~cm}^{-1}$, internal modes related to $\mathrm{TMA}^{+}$prevail, such as the symmetric stretching of the $\mathrm{CH}_{3}$ group and combinations of symmetric stretching and asymmetric stretching of this methyl group. As we will show, these medium-intensity modes are very sensitive to disorder and modifications in the chemical environment of TMA during phase transitions. In this region, we highlight the 2953 and $2978 \mathrm{~cm}^{-1}$ modes that are attributed to pure $\mathrm{CH}_{3}$ symmetric stretching vibrations and those observed at 2921 and $3032 \mathrm{~cm}^{-1}$ that correspond to mixed symmetric and asymmetric stretching modes of the $\mathrm{CH}_{3}$ group.

Table 2. Observed Raman modes (in $\mathrm{cm}^{-1}$ ) of $\mathrm{TMACdN}_{3}$ and their respective assignment.

\begin{tabular}{|c|c|c|c|}
\hline $\begin{array}{c}\mathrm{C} 2 / \mathrm{c} \\
(80 \mathrm{~K})\end{array}$ & $\begin{array}{l}\mathrm{P} 2_{1} / \mathrm{m} \\
(298 \mathrm{~K})\end{array}$ & $\begin{array}{l}\text { Pm-3m } \\
(373 \text { K) }\end{array}$ & Assignment \\
\hline $3044 \mathrm{~m}$ & & & $v_{\mathrm{s}} \mathrm{CH}_{3}$ \\
\hline 3037 s & $3032 \mathrm{~m}$ & $3031 \mathrm{~m}$ & $v_{\mathrm{as}} \mathrm{CH}_{3} v_{\mathrm{s}} \mathrm{CH}_{3}$ \\
\hline $2982 \mathrm{~s}$ & $2978 \mathrm{~m}$ & $2978 \mathrm{~m}$ & $v_{\mathrm{s}} \mathrm{CH}_{3}$ \\
\hline $2972 \mathrm{~m}$ & $2969 \mathrm{sh}$ & $2970 \mathrm{sh}$ & $v_{\mathrm{as}} \mathrm{CH}_{3} v_{\mathrm{s}} \mathrm{CH}_{3}$ \\
\hline $2961 \mathrm{~m} / 2949 \mathrm{~s}$ & $2953 \mathrm{~m}$ & 2954 & $v_{\mathrm{s}} \mathrm{CH}_{3}$ \\
\hline 2917 vw & $2921 \mathrm{~m}$ & $2923 \mathrm{~m}$ & $v_{\mathrm{as}} \mathrm{CH}_{3} v_{\mathrm{s}} \mathrm{CH}_{3}$ \\
\hline $2821 \mathrm{vw}$ & $2820 w$ & $2824 \mathrm{w}$ & $2 x \delta_{\mathrm{as}} \mathrm{CH}_{3}$ \\
\hline $2812 \mathrm{vw}$ & $2813 w$ & 2814 vw & $2 x v_{s}\left(v_{1}\right) \mathrm{N}_{3}^{-}$ \\
\hline 1479 vw & $1481 \mathrm{vw}$ & $1471 \mathrm{vw}$ & $\delta_{\mathrm{as}} \mathrm{CH}_{3} \delta_{\mathrm{s}} \mathrm{CH}_{3}$ \\
\hline $1462 \mathrm{vw}$ & $1453 \mathrm{w}$ & $1451 \mathrm{w}$ & $\delta_{\mathrm{as}} \mathrm{CH}_{3} \delta_{\mathrm{s}} \mathrm{CH}_{3}$ \\
\hline \multirow[t]{2}{*}{$1399 \mathrm{vw}$} & $1440 \mathrm{vw}$ & $1440 \mathrm{vw} /$ & $\begin{array}{l}\text { combination } \\
\text { combination }\end{array}$ \\
\hline & 1366 vs & 1367 s & $v_{\mathrm{s}}\left(v_{1}\right) \mathrm{N}_{3}^{-}$ \\
\hline $1360 \mathrm{vs} / 1355 \mathrm{~m}$ & 1359 vs & 1359 vs/ & $v_{\mathrm{s}}\left(v_{1}\right) \mathrm{N}_{3}$ \\
\hline $1338 \mathrm{w}$ & 1337 vw & $1337 \mathrm{w}$ & \\
\hline $1290 \mathrm{~m}$ & $1289 \mathrm{w}$ & $1285 \mathrm{vw}$ & $\rho \mathrm{CH}_{3}$ \\
\hline $1273 \mathrm{w}$ & & $1267 \mathrm{vw}$ & $\rho \mathrm{CH}_{3}$ \\
\hline $1217 \mathrm{w}$ & $1218 \mathrm{vW}$ & & $\rho \mathrm{CH}_{3}$ \\
\hline $1179 \mathrm{w}$ & $1171 \mathrm{vw}$ & 1174 & $\rho \mathrm{CH}_{3}$ \\
\hline $1170 \mathrm{w}$ & & & $\rho \mathrm{CH}_{3}$ \\
\hline $1045 \mathrm{w}$ & 1047 vw & $1043 \mathrm{w} / 1047 \mathrm{vw}$ & $\rho \mathrm{CH}_{3}$ \\
\hline $958 \mathrm{~m} / 952 \mathrm{~m}$ & $952 \mathrm{w}$ & $950 \mathrm{w}$ & $v_{\mathrm{as}} \mathrm{NC}_{4}$ \\
\hline $762 \mathrm{~m}$ & $758 \mathrm{~m}$ & $759 \mathrm{~m}$ & $v_{\mathrm{S}} \mathrm{NC}_{4}$ \\
\hline $755 \mathrm{~m}$ & $752 \mathrm{sh}$ & 753 w-sh & \\
\hline $730 \mathrm{vw}$ & $741 \mathrm{vw}$ & $741 \mathrm{vw}$ & \\
\hline $609 w$ & $609 w$ & & \\
\hline $463 \mathrm{w} / 453 \mathrm{w}$ & 458 vw & $458 \mathrm{vw}$ & $\delta \mathrm{NC}_{4}$ \\
\hline \multirow[t]{2}{*}{$378 w / 369 w$} & $370 \mathrm{vw}$ & $373 \mathrm{vw}$ & $\delta \mathrm{NC}_{4} \tau \mathrm{CH}_{3}$ \\
\hline & 302 vw-sh & 291 vw-sh & \\
\hline $275 \mathrm{~s}$ & $274 \mathrm{~m}$ & $261 \mathrm{w}$ & $\tau \mathrm{CH}_{3} \mathrm{~T}^{\prime}(\mathrm{Cd})$ \\
\hline 223 vs & $220 \mathrm{~m}$ & $217 w$ & $\mathrm{LN}_{3}^{-}$ \\
\hline $208 s$ & $186 \mathrm{w}$ & $189 \mathrm{w}$ & $\mathrm{LN}_{3}^{-}$ \\
\hline $168 \mathrm{~s}$ & $161 \mathrm{w}$ & $159 w$ & $\mathrm{~T}^{\prime} \mathrm{N}_{3}{ }^{-} \mathrm{T}^{\prime}(\mathrm{Cd})$ \\
\hline $154 \mathrm{~m}$ & $149 \mathrm{~m}$ & $147 \mathrm{~m}$ & \\
\hline $134 \mathrm{w}$ & $137 \mathrm{w}$ & $134 \mathrm{w}$ & \\
\hline $121 \mathrm{~m}$ & $121 \mathrm{w}$ & $117 \mathrm{~m}$ & $\mathrm{~T}^{\prime}(\mathrm{TMA})$ \\
\hline $116 \mathrm{~s} / 115 \mathrm{~m}$ & & & $\mathrm{~T}^{\prime}(\mathrm{TMA})$ \\
\hline $98 \mathrm{w} / 90 \mathrm{~m}$ & $101 \mathrm{w} / 92 \mathrm{vw}$ & $101 \mathrm{w} / 91 \mathrm{w}$ & \\
\hline
\end{tabular}

Key: vs—very strong, s-strong, $\mathrm{m}$-medium, $\mathrm{w}$-weak, vw—very weak; $v_{\mathrm{s}}$-symmetric stretching, $\mathrm{v}_{\mathrm{as}}$-asymmetric stretching, $\delta_{\mathrm{as}}$ - asymmetric bending, $\delta_{\mathrm{s}}-\delta$-symmetric bending (scissoring), $\rho$-rocking, $\tau$ - twisting (torsion), $\mathrm{T}$-translation, L-libration.

\subsubsection{Raman Spectra as a Function of Temperature}

The factor group analysis of the fundamental modes and correlation diagram for the low temperature $\alpha$-phase (space group C2/c) are presented in Table S1 of supplementary materials. Those of the $\gamma$-phase would be similar to the ones already published by M. Trzebiatowska for the $\mathrm{TMMnN}_{3}$ 
compound [24]. Furthermore, since the $\delta$-phase of $\mathrm{TMCdN}_{3}$ is highly disordered, its analysis is not given here.

Figures 4 and 5 show representative normalized Raman spectra of $\mathrm{TMACdN}_{3}$ from $295 \mathrm{~K}$ to $365 \mathrm{~K}$ in the frequency range 30 to $3100 \mathrm{~cm}^{-1}$ and from $80 \mathrm{~K}$ to $290 \mathrm{~K}$ in the range 50 to $3300 \mathrm{~cm}^{-1}$, respectively. In both cases, the dashed lines indicate the critical temperatures for the phase transitions according to DSC, $\mathrm{T}_{\gamma \rightarrow \delta \text { (heating) }}=322 \mathrm{~K}$ (Figure 5) and $\mathrm{T}_{\gamma \rightarrow \beta \rightarrow \alpha(\text { cooling) }}=265 \mathrm{~K}$, temperatures at which significant changes in the Raman spectra also occur (see below).

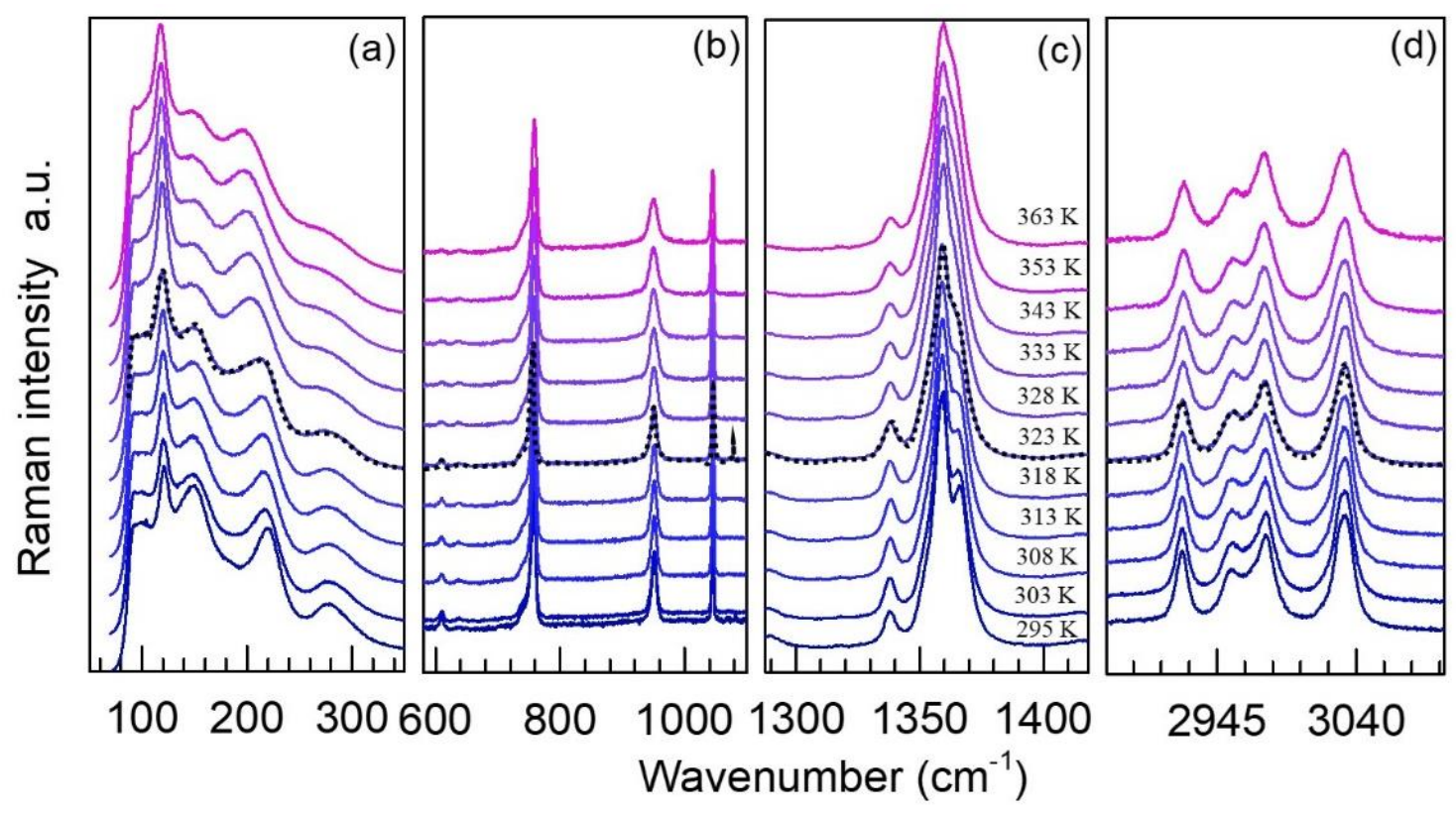

Figure 4. Representative Raman spectra of $\mathrm{TMACdN}_{3}$ at selected temperatures in the region of (a) $30-350 \mathrm{~cm}^{-1}$, (b) $580-1110 \mathrm{~cm}^{-1}$, (c) $1287-1418 \mathrm{~cm}^{-1}$ and (d) $2901-3000 \mathrm{~cm}^{-1}$, normalized to the intensity of the highest peak and shifted vertically for better visualization and comparison. The dashed black line indicates the first-order $(\gamma \rightarrow \delta)$ structural phase transition. In the other regions of the spectral range, as shown in Figure 5b,d, more subtle changes may be noticed and will be discussed below in more detail.

As shown in Figures 4 and 5, the main changes observed in these spectra as temperature increases can be summarized as follows: in first place, a broadening of the modes and, in general, a decrease in their intensity—see, for example, Figure 5a. Especially interesting is the region of $1312-1402 \mathrm{~cm}^{-1}$, corresponding to the azide group $v_{\mathrm{s}}$ modes $\left(v_{1}\right)$, where the band, which is split at low temperatures, seems to merge into one at $\mathrm{T}(\gamma \alpha)$, while a new shoulder at $1366 \mathrm{~cm}^{-1}$ starts to develop in the vicinity of this critical temperature; see Figure $5 c$. For higher temperatures (Figure $4 c$ ), a new approximation of the azide group $v_{\mathrm{s}}$ modes $\left(v_{1}\right)$ at 1359 and $1366 \mathrm{~cm}^{-1}$ takes place, finally giving rise to a broad band.

In order to perform a more detailed analysis of the behavior of the phonons during the temperature-induced multiple structural phase transitions in $\mathrm{TMACdN}_{3}$, we show, in Figures 6 and 7 , the behavior of the most intense modes which were more susceptible to structural changes. In addition, we also include the temperature dependence of their full width at half-maximum (FWHM), which depends on the phonon's lifetime in the lattice and their anharmonicities. As it is well-known, FWHM is very sensitive to structural disorder, whose presence contributes to reducing the phonon's lifetime and consequently increases the width of the spectral bands [32-35]. 


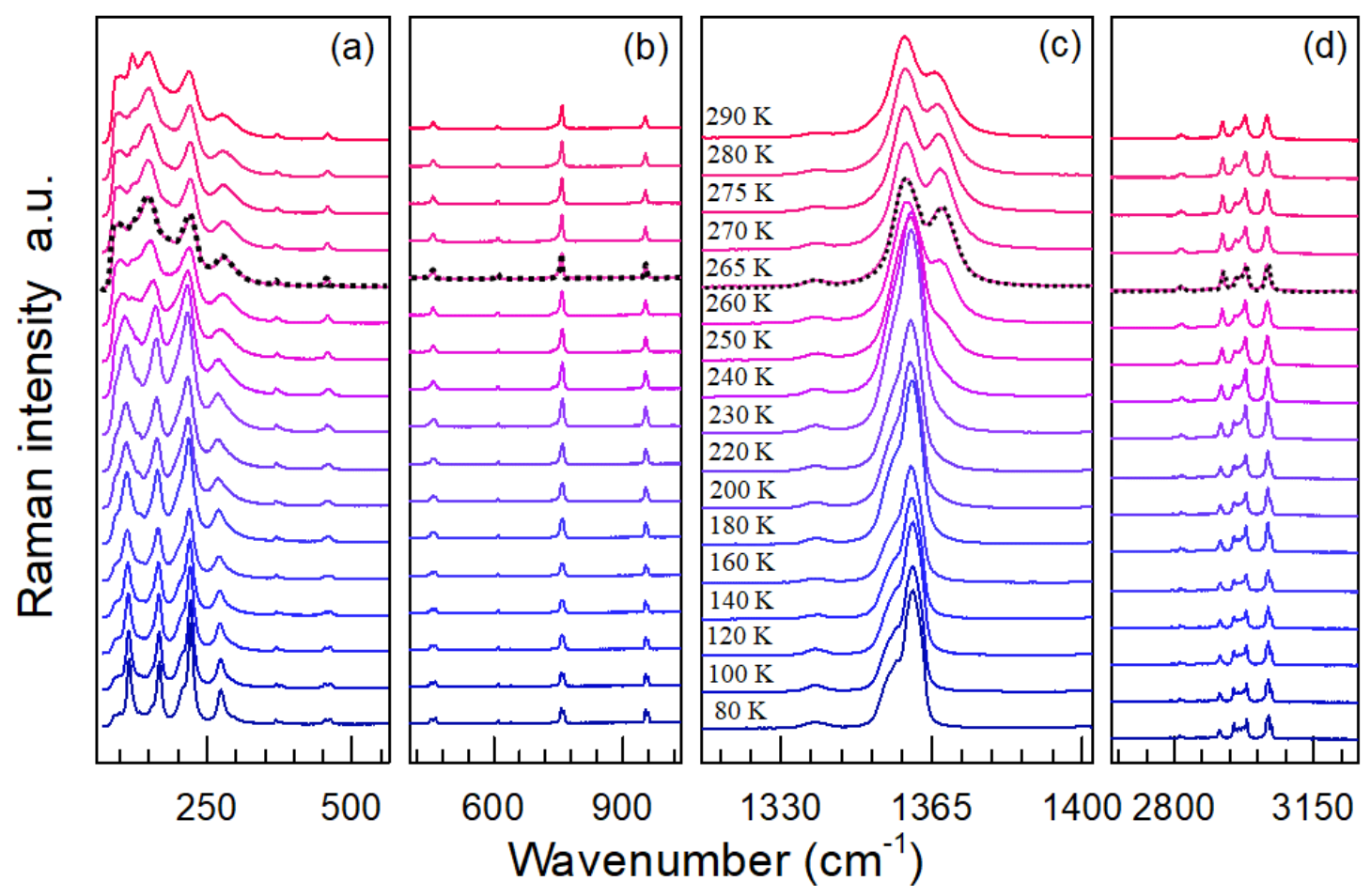

Figure 5. Representative Raman spectra of $\mathrm{TMACdN}_{3}$ at selected temperatures in the region of (a) 64-564 cm $\mathrm{cm}^{-1}$, (b) $403-1035 \mathrm{~cm}^{-1}$, (c) $1312-1402 \mathrm{~cm}^{-1}$ and (d) $2641-3262 \mathrm{~cm}^{-1}$. The dashed black line indicates the first-order $\alpha \rightarrow \beta \rightarrow \gamma$ structural phase transition.

Figure 6 shows the behavior of the wavenumber and FWHM of the modes related to the azide group which can be attributed mainly to the symmetrical stretching vibrations $v_{\mathrm{s}}\left(v_{1}\right) \mathrm{N}_{3}{ }^{-}$. In particular, the very intense band at $1359 \mathrm{~cm}^{-1}$ is presented as the main mode because it remains present, with slight modifications, in all structural phases. As qualitatively explained before, for $\mathrm{T}<265 \mathrm{~K}$ in the low-temperature phase, a splitting is observed and a new mode emerges at $1355 \mathrm{~cm}^{-1}$, while the main mode experiences a red shift to $1361 \mathrm{~cm}^{-1}$. For $265<\mathrm{T}(\mathrm{K})<323$, the main mode experiences a blue shift back to $1359 \mathrm{~cm}^{-1}$ and a new band appears at $1366 \mathrm{~cm}^{-1}$, showing the $\alpha \rightarrow \gamma$ phase transition. In addition, discontinuities in the phonon energy at 1359 and $1366 \mathrm{~cm}^{-1}$ are observed at approximately $323 \mathrm{~K}$ (under heating), where the second structural phase transition $\gamma \rightarrow \delta$ occurs. A strong narrowing and discontinuity in the width of the modes 1359 and $1366 \mathrm{~cm}^{-1}$ are also observed at $323 \mathrm{~K}$; see Figure 6.

We rationalize the observed behavior as follows: at low temperatures, below $265 \mathrm{~K}$, the splitting of the observed symmetrical stretching vibrations $v_{\mathrm{s}}\left(v_{1}\right) \mathrm{N}_{3}{ }^{-}$reflects the presence of two groups of azide ligands, which mainly differ in the degree of interaction with the $\mathrm{H}$ atoms of the TMA cation. Those with stronger azide-H-TMA interactions (and thus with more weakened and more enlarged intraligand N-N bonds) give rise to a lower wavenumber, while those that do not interact with the TMA cation through the $\mathrm{H}$ atoms (and thus with stronger $\mathrm{N}-\mathrm{N}$ intraazide bonds) give rise to higher wavenumber bands; see Figure S4 of supplementary materials. The assignment of azide ligands is reinforced by the temperature dependence of both ligands. The one with stronger interactions shows an increase of wavenumber on heating, which is an anomalous behavior, due to the weakening of this interaction upon heating.

At $265 \mathrm{~K}$, the structural transformation and the concomitant changes in the distances and angles in the azide-framework interaction result in the breaking of $\mathrm{H}$ bonds between the azides that were initially interacting with the framework. Furthermore, a majority of azides get liberated from such bonding and strengthen their intraligand N-N bonds, giving rise to the appearance of a higher number shoulder (about $1367 \mathrm{~cm}^{-1}$ ); see Figure $\mathrm{S} 4$ of supplementary materials. We suggest that the off-center shift of the TMA seems to play an important role at the observed large splitting of the azide group 
symmetrical stretching vibrations. Again, the temperature dependence of both modes upon heating is in agreement with the proposed assignment. The non-interacting azide ligands exhibit a red shift on heating due to the weakening of N-N bond interactions. In contrast, the interacting azide ligand shows a blue shift on heating due to the weakening of the intermolecular interaction and the stronger intramolecular bonding.

Above $\mathrm{T}>332 \mathrm{~K}$, the dynamic forming and breaking of much weaker azide-H-TMA bonds could be the reason for the broad bands observed above that critical temperature.

Furthermore, the strong change observed in the width of the modes could be reflecting variations in the degree of structural disorder in the azide ligands, similar to that observed for TMAMnN 3 and $\mathrm{NaN}_{3}[24,36]$ crystals. Furthermore, the variation in the width of the mode observed at $1359 \mathrm{~cm}^{-1}$ during the $\gamma \rightarrow \delta$ phase transition is abrupt, with a discontinuity, which is, in fact, consistent with the strong increase in the disorder in the azide ligands in the $\delta$ phase.

It should be noted that these results differ significantly from those obtained in the Mn azide [24], where a much broader Raman band for the symmetrical stretching vibration of the azide ligand did not allow to see these changes as a function of temperature.

(a)

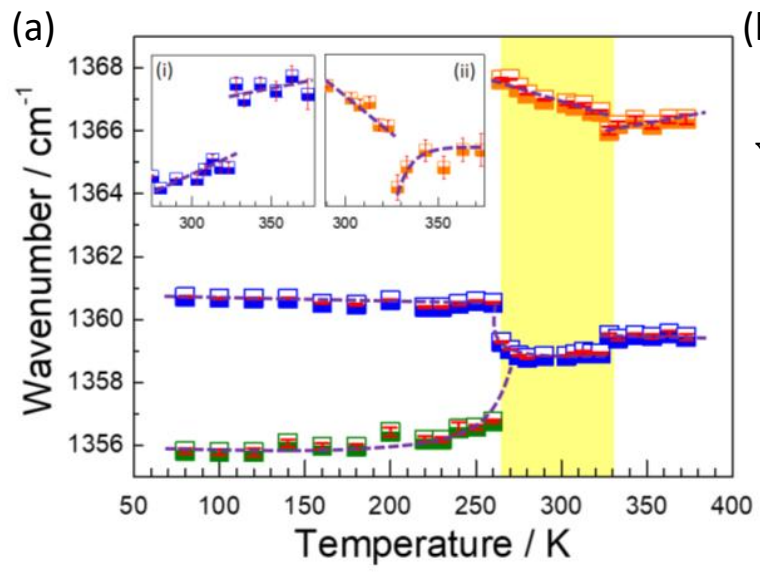

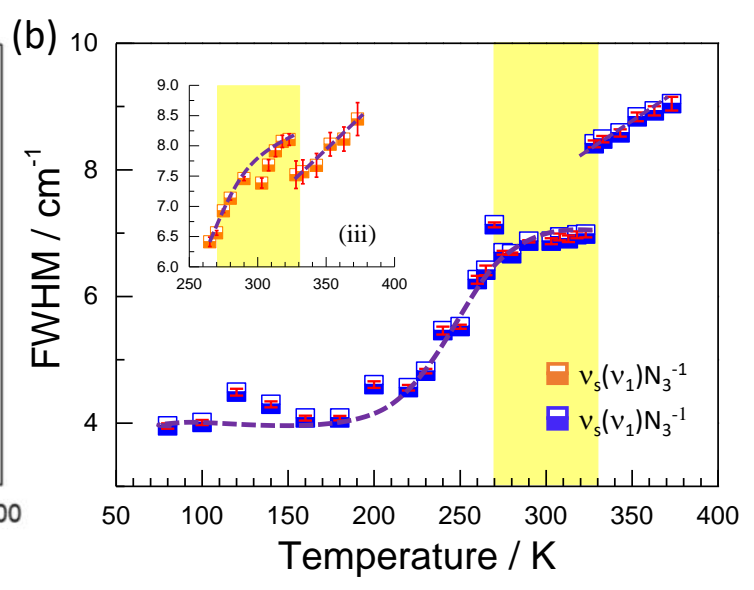

Figure 6. Temperature dependence of the wavenumber (a) and full width at half-maximum (FWHM) (b) of the most representative modes in the region of medium frequencies. The insets (i) and (ii) indicate details of the wavenumber behavior around the second structural phase transition; meanwhile, the inset (iii) indicates details of the multiple phase transitions observed in the width of the mode $1366 \mathrm{~cm}^{-1}$.

On the other hand, Figure 7 shows the behavior of the wavenumber and FWHM of the modes observed at 220, 274 and $758 \mathrm{~cm}^{-1}$ for the entire temperature range studied. Through the anomalies observed in the behavior of these modes, we can also clearly identify the two phase transitions $(\alpha \rightarrow \gamma$ and $\gamma \rightarrow \delta)$ occurring at approximately $265 \mathrm{~K}$ (under cooling) and $323 \mathrm{~K}$ (under heating), both temperatures being in excellent agreement with the DSC measurements. As for the first phase transition $(\alpha \rightarrow \gamma)$, it is observed that the modes at 220 and $274 \mathrm{~cm}^{-1}$ follow a natural softening behavior with an increase in temperature, to subsequently suffer an abrupt increase in energy, an anomalous blue shift of $\sim 4 \mathrm{~cm}^{-1}$, followed by a new softening trend after the transition. Such variations can be mainly attributed to structural changes perceived in the $\mathrm{LN}_{3}{ }^{-}$and $\tau \mathrm{CH}_{3} \mathrm{~T}^{\prime}(\mathrm{Cd})$ vibrations, respectively, probably related to the cooperative tilting of the $\left[\mathrm{CdN}_{6}\right]$ octahedra and concomitant framework distortion that occur at that temperature. As for the behavior of the FWHM of these modes, a sudden broadening is observed with increasing temperature, in agreement with the slight order-disorder effect in the azide ligand in the intermediate phase. 
(a)

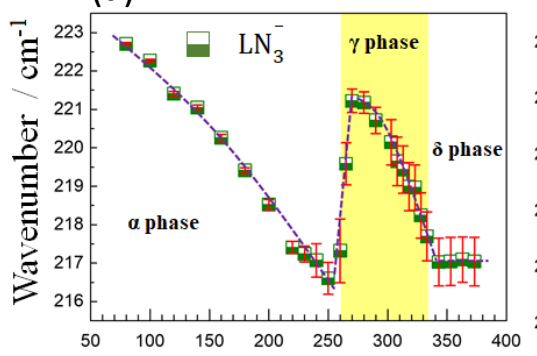

(d) Temperature / K

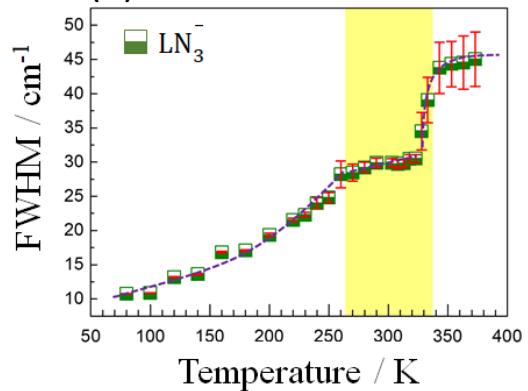

(b)

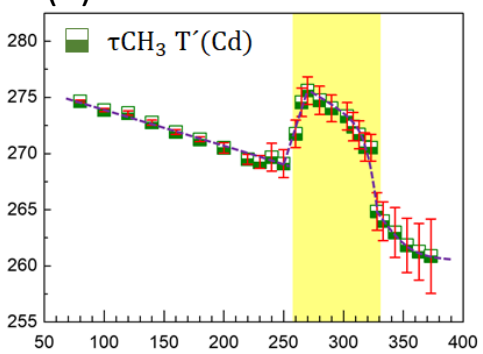

(e) Temperature / K

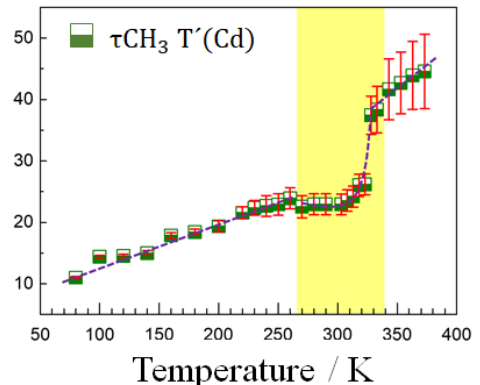

(c)

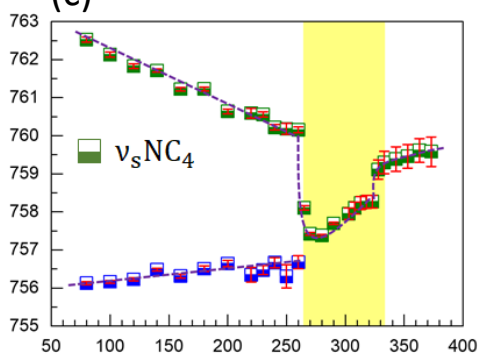

(f) Temperature / K

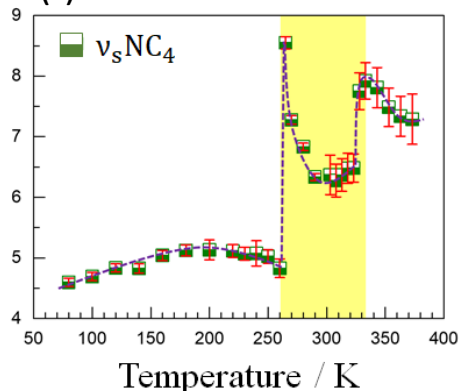

Figure 7. Temperature evolution of the wavenumber $(\mathbf{a}-\mathbf{c})$ and FWHM $(\mathbf{d}-\mathbf{f})$ of the most representative modes in the region of lower frequencies. The half-filled blue and green squares represent experimental data and the solid dotted purple lines represent eye guidelines. The solid vertical lines in red indicate the calculation error bar.

Regarding the $\gamma \rightarrow \delta$ transition, an abrupt variation in the width of the modes at 220 and $274 \mathrm{~cm}^{-1}$, which undergo an increase in width of $\sim 15 \mathrm{~cm}^{-1}$, is observed in contrast to the variation of the same modes at the $\alpha \rightarrow \gamma$ transition. This clearly demonstrates a direct relationship between the FWHM change and the degree of structural disorder since the $\delta$ phase exhibits high structural disorder in the TMA cations and in all crystallographic directions for the $\mathrm{N}_{3}{ }^{-}$ligand. On the other hand, the anomalies observed in the wavenumber were more subtle.

Figure 7 also shows the temperature dependence of the wavenumber and FWHM of the mode at $758 \mathrm{~cm}^{-1}$, characteristic for the $\mathrm{NC}_{4}$ group (TMA), which is split into two modes at temperatures below $265 \mathrm{~K}$ as a result of symmetry reduction and merges into a single one above that critical temperature. It is important to highlight that during the $\alpha \rightarrow \gamma$ transition, the width of this mode is characterized by a strong discontinuity, at difference with the behaviors observed for the widths of the modes at 220 and $274 \mathrm{~cm}^{-1}$. This indicates that short-range disorder effects on TMA cations must be present in the $\alpha \rightarrow \gamma$ transition since the long-range subtle structural changes could not justify such a significant variation in FWHM. Furthermore, during the $\gamma \rightarrow \delta$ phase transition, an anomalous hardening of this mode is observed with increasing temperature, behavior which can be explained by the shortening of the C-N bonds (from 1.486 to $1.492 \AA$ in the $\alpha$-phase to 1.465 to $1.486 \AA$ in the $\gamma$-phase and $1.411 \AA$ in $\delta$ phase [14]), probably related to a strengthening of the N-C bond upon weakening of the TMA-azide interaction.

Finally, Figure 8 shows the temperature dependence of the wavenumber and FWHM of the modes associated with the $\mathrm{CH}_{3}$ group observed at 2921, 2952 and $3032 \mathrm{~cm}^{-1}$. As it can be seen, the frequency of the 2921 and $2952 \mathrm{~cm}^{-1}$ modes has a very similar behavior with temperature, characterized by the anomalous hardening of these modes as temperature increases. Meanwhile, those at higher frequencies $\left(3032 \mathrm{~cm}^{-1}\right)$ follow the expected behavior as a function of temperature, even if with a sharp jump at the phase transitions. 
(a)

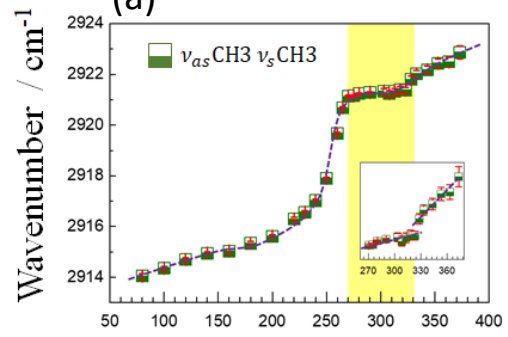

(d) Temperature / $\mathrm{K}$

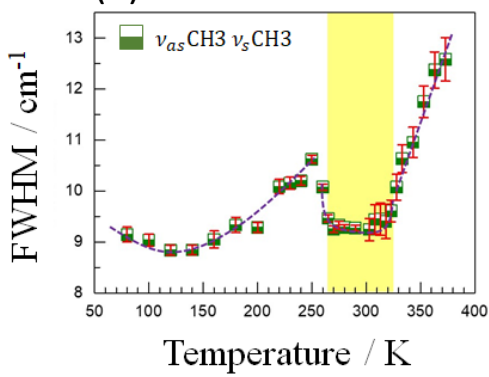

(b)

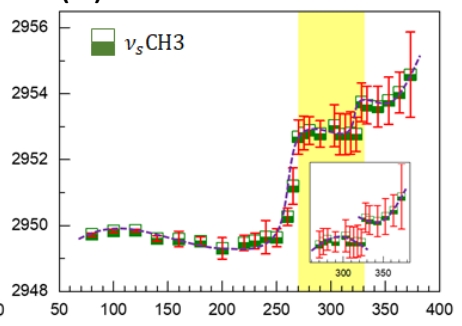

(e) Temperature / $\mathrm{K}$

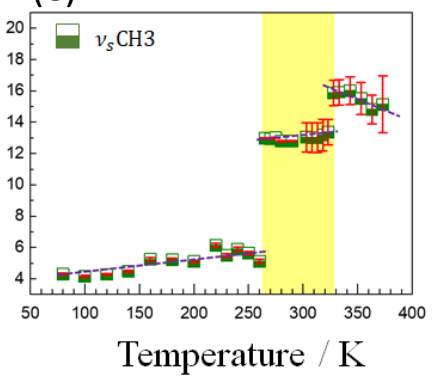

(c)

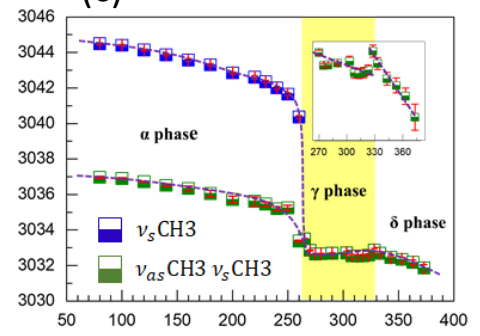

(f) Temperature / K

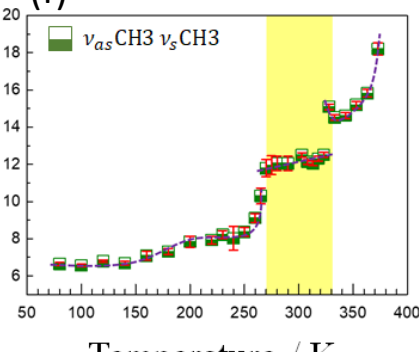

Figure 8. Temperature dependence of the wavenumber $(\mathbf{a}-\mathbf{c})$ and $\mathrm{FWHM}(\mathbf{d}-\mathbf{f})$ of the most representative modes in the region of higher frequencies. The half-filled blue and green squares represent experimental data and the solid dotted purple lines represent eye guidelines. The solid vertical lines in red indicate the calculation error bar. The insets $(\mathbf{a}-\mathbf{c})$ indicate details of the wavenumber behavior around the second structural phase transition.

As for the 2921 and $2952 \mathrm{~cm}^{-1}$ modes, their anomalous behavior is probably related to the fact that they correspond to TMA cations that are interacting with the azides in the framework. In this case, the data reveal a strengthening of the intraatomic $\mathrm{C}-\mathrm{H}$ bond as temperature increases and the azide-H-TMA interaction decreases. In addition, both modes exhibit anomalies that can be easily identified during the $\alpha \rightarrow \gamma$ and $\gamma \rightarrow \delta$ phase transitions. The first anomaly, observed at approximately $323 \mathrm{~K}$, is characterized by an attenuation in the tendency of softening of the modes with temperature reduction. After the second transition at $\sim 265 \mathrm{~K}$ (under cooling), the softening of these modes becomes quite pronounced in good agreement with the changes commented in the azides related to the azide-H-TMA interaction. Such anomalies can also be observed in the width of these modes, which show prominent changes at $\sim 265 \mathrm{~K}$ and $323 \mathrm{~K}$. In particular, the width of the mode $2952 \mathrm{~cm}^{-1}$ undergoes a strong discontinuity $\left(\sim 8 \mathrm{~cm}^{-1}\right)$ at approximately $265 \mathrm{~K}$, which can be associated with a structural disorder of the $\mathrm{CH}_{3}$ group, marking the first transition. Above $323 \mathrm{~K}$, a discontinuity in the width of this mode reveals that the second transition is strongly influenced by the disorder effects of the $\mathrm{CH}_{3}$ group. Regarding the band observed at $3032 \mathrm{~cm}^{-1}$, a splitting of modes occurs at temperatures below $265 \mathrm{~K}$ and a slight change in the trend in the wavenumber during the ferroelastic transition. The width of the mode at $3032 \mathrm{~cm}^{-1}$ also presents clear anomalies near to critical temperatures, proving the structural transitions. Interestingly, the anomalies observed in FWHM in these last three modes related to TMA reinforce that short-range disorder effects are present during the $\alpha \rightarrow \gamma$ structural phase transition and are perceived in the vibrations of the $\mathrm{CH}_{3}$ and $\mathrm{NC}_{4}$ groups, as previously observed in Figure 7. Variations in the short-range configuration certainly contribute to the experimental $\mathrm{N}$ value $(\Delta \mathrm{S}=\mathrm{R} \ln (\mathrm{N}))$ during the $\alpha \rightarrow \gamma$ transition, showing higher values than those observed for the ferroelastic transition (see Table 1 ). 


\section{Materials and Methods}

\subsection{Synthesis}

Block-shaped single crystals of $\mathrm{TMACdN}_{3}$ were obtained by the slow evaporation method as previously reported [15]. An aqueous solution $(10 \mathrm{~mL})$ of $\mathrm{NaN}_{3}(390 \mathrm{mg}, 6 \mathrm{mmol})$ and $\left(\mathrm{CH}_{3}\right)_{4} \mathrm{NCl}$ $(630 \mathrm{mg}, 3 \mathrm{mmol})$ was mixed with an aqueous solution $(5 \mathrm{~mL})$ of $\mathrm{Cd}\left(\mathrm{NO}_{3}\right) 4 \mathrm{H}_{2} \mathrm{O}(154 \mathrm{mg}, 0.5 \mathrm{mmol})$. The resulting solution was filtered through a sieve $(0.22 \mu \mathrm{m})$ and the obtained clear solution was kept at room temperature. After 3 days, transparent crystals were observed at the bottom of the glass.

\subsection{Powder X-ray Diffraction}

Powder X-ray diffraction (PXRD) patterns of the obtained powders and of grounded single-crystals were collected in a Siemens D-5000 diffractometer (Aubrey, TX, USA) using Cu $\mathrm{K}_{\alpha}$ radiation at room temperature.

\subsection{Hirshfeld Surface Analysis}

Identification of close contacts between the framework and the TMA cations in the cavities was carried out by means of Hirshfeld surface analysis using CIF (Crystallographic Information Framework) data [15] and the CrystalExplorer 17.5 software [37].

\subsection{Differential Scanning Calorimetry-DSC}

Differential scanning calorimetric (DSC) analyses were carried out in a TA Instruments DSC Q-2000 (Waters, Cerdanyola del Valles, Spain) by heating and cooling the samples under a nitrogen atmosphere, during several cycles at $10 \mathrm{~K} / \mathrm{min}$.

\subsection{Temperature-Dependent Raman Spectroscopy}

The temperature-dependent Raman measurements were carried out in the 80-373 K range using a Horiba Jobin-Yvon T64000 triple-grating spectrometer (Horiba/Jobin Yvon/ISA, Edison, NJ, USA). For the high- and low-temperature measurements, a Linkam TS1200 heating stage and a CTI-Cryogenic M-22 closed-cycle He refrigerator system were used, respectively. A $532.0 \mathrm{~nm}$ radiation from a Diode-Pumped Solid-State Laser (DPSSL) (Horiba/Jobin Yvon/ISA, Edison, NJ, USA), operating at $\sim 14 \mathrm{~mW}$, was used as the excitation source. The spectra were collected in back-scattering geometry with a resolution of $2 \mathrm{~cm}^{-1}$ on heating, in the case of the high T measurements, and upon cooling, in the case of the low T measurements. An Olympus BX41 microscope equipped with a 20× long working distance (WD $=20.4 \mathrm{~mm}$ ) objective lens was used to focus the laser beam on the sample surface (Olympus, Center Valley, PA, USA), and the Raman signal was detected with an N2-cooled Charge-Coupled Device (CCD) (Olympus, Center Valley, PA, USA).

\section{Conclusions}

Crystals of the azide compound $\left[\mathrm{N}\left(\mathrm{CH}_{3}\right)_{4}\right]\left[\mathrm{Cd}\left(\mathrm{N}_{3}\right)_{3}\right]$ belonging to the hybrid organic-inorganic perovskite family were obtained by the slow evaporation method. DSC measurements demonstrated that the compound experiences multiple structural transitions, with a total entropy change of $|\Delta S|$ $\sim 62.09 \mathrm{~J} \cdot \mathrm{kg}^{-1} \mathrm{~K}^{-1}$. The estimated barocaloric coefficient, $\left(\delta \mathrm{T}_{\mathrm{t}} / \delta \mathrm{P}\right)$, gives values of 12.39 and $-6.52 \mathrm{~K}$ $\operatorname{kbar}^{-1}$ for the $\alpha \rightarrow \beta \rightarrow \gamma$ and the ferroelastic phase transitions, respectively. These values are very large in comparison with BC inorganic compounds (such as alloys and oxides) and similar to those found in the analogous $\mathrm{TMAMnN}_{3}$ hybrid perovskite [18]. Very interestingly, the ferroelastic transition displays an inverse BC coefficient, which is very scarce, and few materials are known to exhibit this behavior. In addition, its working temperature is close to room temperature, between 260 and $320 \mathrm{~K}$. All these findings indicate that $\mathrm{TMACdN}_{3}$ is an interesting material for $\mathrm{BC}$ applications. 
On the other hand, a detailed study of the temperature dependence of Raman modes between 80 and $373 \mathrm{~K}$ was carried out. In this context, the internal vibration groups of the TMA cation and the $\mathrm{N}_{3}{ }^{-}$azide ligand and the lattice vibrations were distinguished in specific spectral bands, allowing classifications of the modes and individualized monitoring of the vibrations by molecular groups as a function of temperature. In the vicinity of the critical temperatures of the $\alpha \rightarrow \gamma$ and $\gamma \rightarrow \delta$ transitions, the vibrational frequencies and FWHMs exhibited clear anomalies, indicating the onset of the first-order structural phase transitions. From analysis of the variation of TMA and azide modes with temperature, it was observed that many modes follow the conventional red shift upon heating, while other modes exhibit an unconventional blue shift, which were related to the weakening of intermolecular interactions and the strengthening of intramolecular bonding, respectively.

Abrupt variations in the width of the modes related to $\mathrm{TMA}^{+}$, particularly in the vibrations of symmetric and asymmetric stretching of $\mathrm{CH}_{3}$ molecular group and the symmetric stretching of the $\mathrm{NC}_{4}$ group, indicate that short-range disorder effects are present during the $\alpha \rightarrow \gamma$ structural transition.

These results show that Raman spectroscopy is a powerful tool to gain information about phase transitions and intermolecular interactions between the A-cation and the framework, even at disordered phases, in complex hybrid organic-inorganic perovskites.

Supplementary Materials: The following are available online, Figure S1: (above) Experimental X-ray powder diffraction pattern of the TMACdN3 sample at room temperature, and (below), the simulated X-ray powder diffraction pattern of TMACdN3 obtained from the single crystal measured data, Figure S2: Perspective view along the c-axis of the crystal structure of the TMACdN3 $\gamma$-phase, showing the unconventional cooperative tilting of the $\left[\mathrm{CdN}_{6}\right]$ octahedra, Figure S3: Hirshfeld surfaces of TMACdN 3 for the $\alpha$-phase (S.G:C2/c) and $\gamma$-phase (S.G.: $\mathrm{P} 21 / \mathrm{m}$ ) showing in red interactions between the azido ligands in the framework and the TMA cations, Figure S4: Fig. S4. Temperature dependence of the wavenumber of the symmetrical stretch vibrations s(1)N3- and the assignment of azido ligands (right figure). Structural destails of $\alpha$-phase (S.G: C2/c) and $\gamma$-phase (S.G.: P21/m) showing the different crystalloghaphic azido ligands (left image).

Author Contributions: Conceptualization, M.A.S.-R., R.X.d.S. and A.N.A.d.A.S.; methodology, C.W.d.A.P., C.C.d.S. and M.S.-A.; investigation, J.S.-B., A.G.-F. and R.X.d.S.; data analysis, A.N.A.d.A.S., C.C.d.S., J.S.-B. and R.X.d.S.; data interpretation, A.N.A.d.A.S., C.C.d.S., M.S.-A., M.A.S.-R. and R.X.d.S.; writing-original draft preparation, C.C.d.S., R.X.d.S. and C.W.d.A.P.; writing-review and editing, M.S.-A.; supervision, M.A.S.-R. All authors have read and agreed to the published version of the manuscript.

Funding: The authors thank the Brazilian agencies CNPq (Project No. 431943/2016-8) and FAPEMA, Fundação de Amparo à Pesquisa e ao Desenvolvimento Científico e Tecnológico do Maranhão (Project No. COOPI-07771/17), the Spanish Ministerio de Economía y Competitividad (MINECO) and EU-FEDER under the project MAT2017-86453-R and Xunta de Galicia under the project ED431G/09 for financial support towards this work.

Conflicts of Interest: The authors declare no conflict of interest.

\section{References}

1. Li, W.; Wang, Z.; Deschler, F.; Gao, S.; Friend, R.H.; Cheetham, A.K. Chemically diverse and multifunctional hybrid organic-inorganic perovskites. Nat. Rev. Mater. 2017, 2. [CrossRef]

2. García-fernández, A.; Juarez-perez, E.J.; Bermúdez-, J.M.; Llamas-saiz, A.L.; Artiaga, R.; López-beceiro, J.J. Hybrid Lead Halide DMAPbX3 (X = Cl- and Br-) Perovskites with Multiple Functional Properties. J. Mater. Chem. C 2019, 7, 10008-10018. [CrossRef]

3. Kojima, A.; Teshima, K.; Shirai, Y.; Miyasaka, T. Organometal Halide Perovskites as Visible-Light Sensitizers for Photovoltaic Cells. J. Am. Chem. Soc. 2009, 131, 6050-6051. [CrossRef] [PubMed]

4. Zhang, W.; Xiong, R.-G. Ferroelectric Metal-Organic Frameworks. Chem. Rev. 2011, 112, $1163-1195$. [CrossRef] [PubMed]

5. Gómez-Aguirre, L.C.; Pato-Doldán, B.; Mira, J.; Castro-García, S.; Señarís-Rodríguez, M.A.; Sánchez-Andújar, M.; Singleton, J.; Zapf, V.S. Magnetic Ordering-Induced Multiferroic Behavior in [CH3NH3][Co(HCOO)3] Metal-Organic Framework. J. Am. Chem. Soc. 2016, 138, 1122-1125. [CrossRef] [PubMed]

6. Gómez-Aguirre, L.C.; Pato-Doldán, B.; Stroppa, A.; Yang, L.-M.; Frauenheim, T.; Mira, J.; Yañez-Vilar, S.; Artiaga, R.; Castro-García, S.; Sánchez-Andújar, M.; et al. Coexistence of Three Ferroic Orders in the Multiferroic Compound [(CH3 )4 N][Mn(N3 )3 ] with Perovskite-Like Structure. Chem. A Eur. J. 2016, 22, 7863-7870. [CrossRef] [PubMed] 
7. Bermúdez-García, J.M.; Sánchez-Andújar, M.; Señarís-Rodríguez, M.A. A New Playground for Organic-Inorganic Hybrids: Barocaloric Materials for Pressure-Induced Solid-State Cooling. J. Phys. Chem. Lett. 2017, 8, 4419-4423. [CrossRef]

8. Bermúdez-García, J.M.; Sánchez-Andújar, M.; Castro-García, S.; López-Beceiro, J.; Artiaga, R.; Señarís-Rodríguez, M.A. Giant barocaloric effect in the ferroic organic-inorganic hybrid [TPrA][Mn(dca)3] perovskite under easily accessible pressures. Nat. Commun. 2017, 8, 15715. [CrossRef]

9. Saparov, B.; Mitzi, D.B. Organic-Inorganic Perovskites: Structural Versatility for Functional Materials Design. Chem. Rev. 2016, 116, 4558-4596. [CrossRef]

10. Mitzi, D.B. Templating and structural engineering in organic-inorganic perovskites. J. Chem. Soc. Dalton Trans. 2001, 1-12. [CrossRef]

11. Kieslich, G.; Sun, S.; Cheetham, A.K. An extended Tolerance Factor approach for organic-inorganic perovskites. Chem. Sci. 2015, 6, 3430-3433. [CrossRef] [PubMed]

12. Zhao, X.-H.; Huang, X.-C.; Zhang, S.-L.; Shao, D.; Wei, H.-Y.; Wang, X.-Y. Cation-Dependent Magnetic Ordering and Room-Temperature Bistability in Azido-Bridged Perovskite-Type Compounds. J. Am. Chem. Soc. 2013, 135, 16006-16009. [CrossRef]

13. Kieslich, G.; Sun, S.; Cheetham, A.K. Solid-state principles applied to organic-inorganic perovskites: New tricks for an old dog. Chem. Sci. 2014, 5, 4712-4715. [CrossRef]

14. Du, Z.-Y.; Zhao, Y.-P.; He, C.-T.; Wang, B.-Y.; Xue, W.; Zhou, H.-L.; Bai, J.; Huang, B.; Zhang, W.-X.; Chen, X.-M. Structural Transition in the Perovskite-like Bimetallic Azido Coordination Polymers: (NMe4)2[B' $\left.B^{\prime \prime}(\mathrm{N} 3) 6\right]$ $\left(\mathrm{B}^{\prime}=\mathrm{Cr} 3+, \mathrm{Fe} 3+; \mathrm{B}^{\prime \prime}=\mathrm{Na}+, \mathrm{K}+\right)$. Cryst. Growth Des. 2014, 14, 3903-3909. [CrossRef]

15. Du, Z.-Y.; Zhao, Y.-P.; Zhang, W.-X.; Zhou, H.-L.; He, C.-T.; Xue, W.; Wang, B.-Y.; Chen, X.-M. Above-room-temperature ferroelastic phase transition in a perovskite-like compound [N(CH3)4][Cd(N3)3]. Chem. Commun. 2014, 50, 1989-1991. [CrossRef]

16. Mautner, F.A.; Cortés, R.; Lezama, L.; Lu, J. [N(CH3)4][Mn(N3)3]: A Compound with a Distorted Perovskite Structure through Azido Ligands. Angew. Chem. Int. Ed. 1996, 35, 78-80. [CrossRef]

17. Ribas, J.; Monfort, M.; Díaz, C.; Bastos, C.; Solans, X. New antiferromagnetic dinuclear complexes of nickel(II) with two azides as bridging ligands. Magneto-structural correlations. Inorg. Chem. 1993, 32, 3557-3561. [CrossRef]

18. Salgado-Beceiro, J.; Nonato, A.; Silva, R.X.; García-Fernández, A.; Sánchez-Andújar, M.; Castro-Garcia, S.; Stern-Taulats, E.; Señarís-Rodríguez, M.A.; Moya, X.; Bermúdez-García, J.M. Near-room-temperature reversible giant barocaloric effects in [(CH3)4N]Mn[N3]3 hybrid perovskite. Mater. Adv. 2020. [CrossRef]

19. Wei, W.; Li, W.; Butler, K.T.; Feng, G.; Howard, C.J.; Carpenter, M.P.; Lu, P.; Walsh, A.; Cheetham, A.K. An Unusual Phase Transition Driven by Vibrational Entropy Changes in a Hybrid Organic-Inorganic Perovskite. Angew. Chem. Int. Ed. 2018, 57, 8932-8936. [CrossRef]

20. Moreira, R.L.; Matinaga, F.M.; Dias, A. Raman-spectroscopic evaluation of the long-range order in $\mathrm{Ba}(\mathrm{B}[\mathrm{sub}$ 1/3][sup ']B[sub 2/3][sup "])O[sub 3] ceramics. Appl. Phys. Lett. 2001, 78, 428-430. [CrossRef]

21. Mączka, M.; Da Silva, T.A.; Paraguassu, W.; Da Silva, K.P. Raman scattering studies of pressure-induced phase transitions in perovskite formates $[(\mathrm{CH} 3) 2 \mathrm{NH} 2][\mathrm{Mg}(\mathrm{HCOO}) 3]$ and $[(\mathrm{CH} 3) 2 \mathrm{NH} 2][\mathrm{Cd}(\mathrm{HCOO}) 3]$. Spectrochim. Acta Part A Mol. Biomol. Spectrosc. 2016, 156, 112-117. [CrossRef] [PubMed]

22. Liu, Y.; Liu, H.; Kim, H.-S.; Yang, M.; Yue, N.; Ren, G.; Zhu, K.; Liu, S.; Park, N.-G.; Zhang, Y.; et al. Multiple-Stage Structure Transformation of Organic-Inorganic Hybrid Perovskite CH3NH3PbI3. Phys. Rev. X 2016, 6, 1-20. [CrossRef]

23. Ptak, M.; Mączka, M.; Gagor, A.; Sieradzki, A.; Stroppa, A.; Di Sante, D.; Perez-Mato, J.M.; Macalik, L. Experimental and theoretical studies of structural phase transition in a novel polar perovskite-like [C2H5NH3][Na0.5Fe0.5(HCOO)3] formate. Dalton Trans. 2016, 45, 2574-2583. [CrossRef] [PubMed]

24. Trzebiatowska-Gusowska, M.; Ptak, M. The mechanism of phase transitions in azide perovskites probed by vibrational spectroscopy. Spectrochim. Acta Part A Mol. Biomol. Spectrosc. 2019, 214, 184-191. [CrossRef] [PubMed]

25. Leguy, A.M.A.; Goñi, A.R.; Frost, J.M.; Skelton, J.; Brivio, F.; Rodríguez-Martínez, X.; Weber, O.J.; Pallipurath, A.; Alonso, M.I.; Campoy-Quiles, M.; et al. Dynamic disorder, phonon lifetimes, and the assignment of modes to the vibrational spectra of methylammonium lead halide perovskites. Phys. Chem. Chem. Phys. 2016, 18, 27051-27066. [CrossRef] 
26. Mączka, M.; Pietraszko, A.; Macalik, B.; Hermanowicz, K. Structure, Phonon Properties, and Order-Disorder Transition in the Metal Formate Framework of [NH4][Mg(HCOO)3]. Inorg. Chem. 2014, 53, 787-794. [CrossRef]

27. Trzebiatowska, M.; Mączka, M.; Ptak, M.; Giriunas, L.; Balciunas, S.; Šimènas, M.; Klose, D.; Banys, J. Spectroscopic Study of Structural Phase Transition and Dynamic Effects in a [(CH3)2NH2][Cd(N3)3] Hybrid Perovskite Framework. J. Phys. Chem. C 2019, 123, 11840-11849. [CrossRef]

28. Hanna, S.; Mautner, F.; Koppelhuber-Bitschnau, B.; Abu-Youssef, M. Preparation and Study of Phase Transformation of the Azido Complex [N(CH3)4][CD(N3)3] by X-Ray Powder Diffraction and DSC. Mater. Sci. Forum 2000, 321, 1098-1101. [CrossRef]

29. Mañosa, L.; Planes, A. Materials with Giant Mechanocaloric Effects: Cooling by Strength. Adv. Mater. 2016, 29, 11. [CrossRef]

30. Mhiri, A.; Krichen, F.; Oueslati, A.; Lhoste, J.; Goutenoire, F.; Gargouri, M.; Bulou, A. Synthesis, structural characterization and spectroscopic studies of bis tetramethylammonium hexabromostannate [N(CH3)4]2SnBr6. J. Alloys Compd. 2019, 772, 546-556. [CrossRef]

31. Maczka, M.; Ptak, M.; Macalik, L. Infrared and Raman studies of phase transitions in metal-organic frameworks of [(CH3)2NH2][M(HCOO)3] with M=Zn, Fe. Vib. Spectrosc. 2014, 71, 98-104. [CrossRef]

32. Simonis, G.J.; Hathaway, C.E. Raman spectrum and phase transition in sodium azide. Phys. Rev. B 1974, 10, 4419-4433. [CrossRef]

33. Chitnis, A.; Bhatt, H.; Mączka, M.; Deo, M.N.; Garg, N.; Deo, M.N. Remarkable resilience of the formate cage in a multiferroic metal organic framework material: Dimethyl ammonium manganese formate (DMAMnF). Dalton Trans. 2018, 47, 12993-13005. [CrossRef]

34. Trzebiatowska-Gusowska, M.; Gagor, A. The order-disorder state of diaminoalkanes in Cu-based metal-organic materials. J. Coord. Chem. 2017, 70, 1536-1547. [CrossRef]

35. Szymborska-Małek, K.; Trzebiatowska-Gusowska, M.; Mączka, M.; Gagor, A. Temperature-dependent IR and Raman studies of metal-organic frameworks [(CH3)2NH2][M(HCOO)3], M=Mg and Cd. Spectrochim. Acta Part A Mol. Biomol. Spectrosc. 2016, 159, 35-41. [CrossRef] [PubMed]

36. Aghdaee, S.R.; Rae, A.I.M. The phase transition in sodium azide. J. Chem. Phys. 1983, 79, 4558. [CrossRef]

37. Spackman, M.A.; Jayatilaka, D. Hirshfeld surface analysis. Cryst. Eng. Commun. 2009, 11, 19-32. [CrossRef]

Sample Availability: Samples of the compound [(CH3)4N][Cd(N3)3] is available from the authors.

Publisher's Note: MDPI stays neutral with regard to jurisdictional claims in published maps and institutional affiliations.

(C) 2020 by the authors. Licensee MDPI, Basel, Switzerland. This article is an open access article distributed under the terms and conditions of the Creative Commons Attribution (CC BY) license (http://creativecommons.org/licenses/by/4.0/). 